\section{Prevalence of gastrointestinal zoonotic helminths in dogs of Kathmandu, Nepal}

\author{
Satyal RC, ${ }^{*}$ Manandhar S,1,2 Dhakal S,1,3 \\ Mahato BR, ${ }^{1}$ Chaulagain $S,{ }^{1}$ Ghimire $L,{ }^{1}$ \\ Pandeya YR ${ }^{1}$
}

\footnotetext{
${ }^{1}$ Institute of Agriculture and Animal Science (IAAS), Tribhuvan University, Chitwan, Nepal, ${ }^{2}$ Frie University, Berlin, Germany and Chang Mai University, Thailand, Veterinary Standards and Drugs Administration Office, Tripureshwor, Kathmandu, Nepal, ${ }^{3}$ Ohio State University, Ohio, USA
}

*Correspondence to: Dr. Ram Chandra Satyal, Institute of Agriculture and Animal Science, (IAAS), Tribhuvan University, Rampur, Chitwan, Nepal, email: krh.phulbari@gmail.com, Tel No.: (+977)- 9841696017

\begin{abstract}
INTRODUCTION: Considering the close association of dog and human beings and increasing trend of pet rearing, it is important to know the status of zoonotic helminths of pet and stray dogs and awareness of owners about this in Kathmandu, Nepal. This study was carried out to determine the prevalence of gastrointestinal zoonotic helminth parasites in dogs and to assess the awareness about canine helminth zoonoses in pet owners.
\end{abstract}

MATERIALS AND METHODS: This cross-sectional study was conducted from September- 2012 to December- 2013. A total of 210 fecal samples (105 each from pet and stray dogs) were collected perrectally and examined by using Formalin-Ether Concentration method. Questionnaire survey was carried out among dog owners.

RESULTS: The prevalence of gastrointestinal helminths was $46.7 \%$ (98/210). Out of 98 positive samples five different parasite species observed were Ancylostoma spp. 52.0\% (51/98), Toxocara canis 41.8\% (41/98), Taenia/Echinococcus spp. 15/98 (15.3\%), Dipylidium caninum, 9.2\% (9/98), and Trichuris vulpis, $5.1 \%$ (5/98). Prevalence was higher in stray dogs $(56.2 \%$ vs. $37.1 \%)(\mathrm{p}<0.05)$; in females ( $51.6 \%$ vs. $39.8 \%$ ) ( $p>0.05)$; in younger dogs up to 2 years of age (56.3\% vs. $35.7 \%)$ $(\mathrm{p}<0.05)$; in non-dewormed dogs $(72.7 \%$ vs. $33.0 \%)(p<0.05)$ and in dogs sharing rooms with owner $(46.1 \%$ vs. $13.8 \%$ ) ( $\mathrm{p}<0.05)$. Only $11.4 \%$ of the owners surveyed were aware about canine helminth zoonoses.

CONCLUSIONS: Due to potential risk of zoonotic helminths to human beings and low level of zoonoses awareness in pet owners, there is need of generating awareness to pet owners regarding periodic anthelminthic treatment of pet dogs and other prevention and control measures.

KEY WORDS: Gastrointestinal helminth, Zoonoses, Dog, Kathmandu, Awareness

Article submitted 12 July. Reviewed 28 July. Author correction 10August. Final version accepted 18 August 2013. 


\section{INTRODUCTION}

Dogs are associated with more than 60 zoonotic diseases transmission including the helminth parasites which can pose serious public health concern worldwide. ${ }^{1}$ Dogs in fact, are the definite host for various intestinal parasites which can cause severe zoonotic diseases like hydatidosis caused by Echinococcus granulosus. ${ }^{2}$ The increasing trend of pet rearing and huge number of stray dogs that coexist with human dwellings in the city area of developing nations bring about great quantity of dogs' feces to constitute a potential risk of infection for human beings. Playgrounds, parks, gardens, temples and other public places may serve as potential source of healthy dog infection as well as human infection due to contamination of these places by infected dogs' feces. Human transmission occurs either directly through the infected dog or indirectly through consumption of contaminated foods and water. Furthermore, the low level of hygienic conditions, lack of sufficient veterinary attention and zoonotic disease awareness compounds the risk of transmission of these diseases to human.,4 Kathmandu is the most populous city and capital of Nepal and there is huge population of stray dogs. ${ }^{5}$ However, there is very limited research on canine gastrointestinal (GI) zoonotic helminths in this city. Thus the present study was aimed to determine prevalence of zoonotic gastrointestinal helminths in dogs (both stray and pet dogs) and assess the awareness of pet owners about helminths zoonoses from dogs.

\section{MATERIALS AND METHODS}

This cross-sectional study was carried out from September to December 2012 in Kathmandu district of Nepal. The district is located from 27'27"E to $27^{\prime} 49^{\prime \prime} \mathrm{E}$ and $85^{\prime} 10 " \mathrm{~N}$ to $85^{\prime} 32 \mathrm{~N} \mathrm{~N}$ with an altitude ranging between $1262 \mathrm{~m}$ to $2732 \mathrm{~m}$ above the sea level. This is the capital city of Nepal, highly populous and harbors huge number of stray as well as pet dogs. Stray dogs' fecal samples were collected from Kathmandu Animal Treatment Centre, Chapaligaun where dogs were rescued from different areas of Kathmandu district for neutering and other medicinal purposes. Pet dogs' fecal samples were collected from Central Veterinary Hospital, Tripureshwor, Kathmandu Veterinary Clinic, Maharajgunj and by individual household visits in the uncovered areas of Kathmandu. A total of 210 fecal samples (105 from stray and 105 from pet dogs) were collected per-rectally with the gloves on hand and kept in a zip lock poly bags containing about 20 drops $(1 \mathrm{ml})$ of $10 \%$ formalin. Each bag was well labeled mentioning type of dog (stray or pet), age, sex, date and time of collection. The samples were then immediately taken to the Central Veterinary Laboratory, Tripureshwor for parasitological procedures. Collected fecal samples were analyzed qualitatively by using Formalin-Ether (FE) concentration method for detecting the presence of eggs of helminth parasites. ${ }^{6}$ Results were considered positive when at least one parasitic egg was present. Different eggs observed under $10 \mathrm{X}$ and $40 \mathrm{X}$ magnifications were identified to the level of genera or species possible. ${ }^{7,8}$

A questionnaire survey was conducted to 105 dog owners whose dogs were selected in study regarding the awareness of canine helminth zoonoses. Data were analyzed by using descriptive statistics through SPSS version 19 and MS-Excel, 2007. Effect of dog type (stray or pet), sex, age, deworming pattern and defecation pattern on the zoonotic helminths prevalence was evaluated by Chi-square $\left(\chi^{2}\right)$ test. Values of $p<0.05$ were considered significant.

\section{RESULTS}

Out of 210 fecal samples 98 (46.7\%) were positive with zoonotic helminths. There was higher occurrence of single helminth parasitic infection i.e. $79.6 \%(78 / 98)$ than concurrent mixed infection in $20.4 \%$ (20/98). Among stray dogs 56.2\% (59/105) and in pet dogs $37.1 \%(39 / 105)$ were positive. There was significant difference in zoonotic helminth positivity between stray and pet dogs $(p<0.05)$. Out of 98 positive samples five different helminths parasitic species were observed which is shown in graph (Figure). Of them Ancylostoma spp. and Toxocara canis were the predominant parasites and Trichuris vulpis was the least dominant parasites.

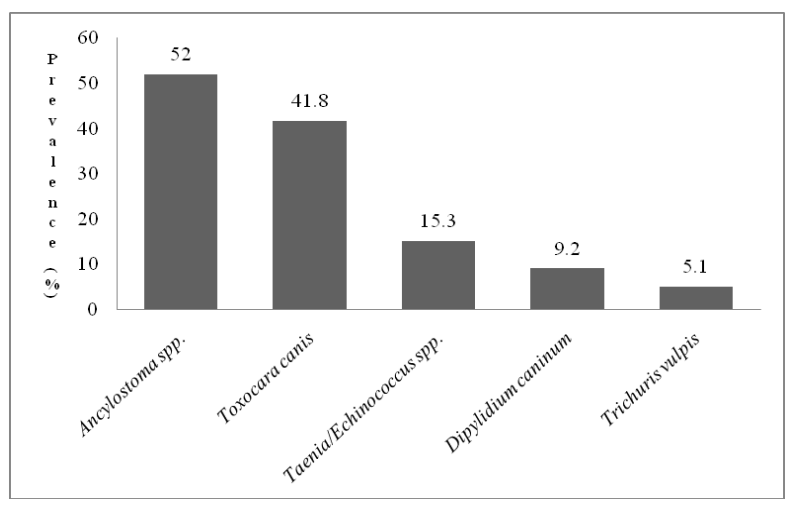

Figure. Species wise prevalence of GI zoonotic helminthes 
Zoonotic helminth infestation was significantly higher $(\mathrm{p}<0.05)$ in dogs of age up to 2 years with $56.25 \%(63 / 112)$ than in older dogs with prevalence $35.71 \%$ (35/98). Prevalence in females was $51.6 \%(35 / 98)$ whereas that in males was $39.8 \%(35 / 88)$ but not significantly different ( $p>0.05)$ In case of pet dogs the prevalence was significantly higher $(\mathrm{p}<0.05)$ in non-dewormed dogs and was $72.73 \%(8 / 11)$ than in dewormed dogs which was $32.97 \%$ (31/94). Significantly higher $(p<0.05)$ prevalence of $46.05 \%(35 / 76)$ was found in dogs which shared room with owners than the dogs which were confined in the kennel $13.8 \%$ (4/29). Likewise, prevalence was $48.15 \%(13 / 27)$ in pet dogs which were taken outside for defecation whereas that in which were allowed to defecate within compound premises was 33.33\% (26/78). Out of 105 pet owners surveyed 79\% (83/105) were aware that they can get diseases from dogs but only $11.4 \%(12 / 105)$ were aware of canine helminth zoonoses.

\section{DISCUSSION}

In Kathmandu $46.7 \%$ of dogs were found to be infected with GI zoonotic helminths. This finding is higher than one previous study finding in Nepal that revealed $41.3 \%$ prevalence. ${ }^{9}$ This finding however, was lower than findings in Tanzania ${ }^{10}$ and Ethiopia $^{11}$ which were $59.3 \%$ and $90.7 \%$ respectively. Various factors like geography, diagnostic technique, demographic features and antihelminthic usage can be responsible for such variation. ${ }^{12}$ Ancylostoma spp. had highest prevalence followed by Toxocara canis, Taenia/Echinococcus spp., Dipylidium caninum and Trichuris vulpis. This finding is also supported by the previous studies in Nepal $^{9}$, Tanzania ${ }^{10}$ and Ethiopia $^{11,13}$ respectively. The infection rate was significantly higher in stray dogs $(\mathrm{p}<0.05)$. The lack of antihelmintic treatment is the reason for higher positivity in stray dogs. Significantly higher prevalence in younger dogs $(\mathrm{p}<0.05)$ might be because of underdeveloped immune system of younger dogs. This finding is in accordance with that of previous study in Nepal. ${ }^{9}$ Females were more affected than males but not significantly different. Sex wise prevalence showed higher positivity in female dogs than in males but not significant ( $p>0.05)$. Study of Ethiopia also showed similar findings. ${ }^{14}$ In case of pet dogs the prevalence was significantly higher in non-dewormed dogs $(p<0.05)$. Deworming should be done regularly but lack of that increases the risk of parasitic infection. The finding of significantly higher infection in dogs that share room with owners than those kept in kennel $(p<0.05)$ shows the risk existing for the pet owners through the companion dogs. This also suggests for the importance of kennel for reducing risk of zoonotic helmithosis in human beings from dogs. Higher infection rate in pet dogs taken out of home for defecation might be due to possible contact of pets with stray dogs and/or ingestion of helminths contaminated feeds during outing. Very low level of awareness was found among the pet owners regarding canine zoonotic helminths. It shows that there is need of appropriate public awareness and proper counseling program to the pet owners from governmental and other concerned organizations.

\section{CONCLUSIONS}

This study showed that there is high prevalence of zoonotic helminth parasite in dogs of Kathmandu whether they are stray or pet dogs. This can be a potential source of infection to other healthy dogs and human beings. The prevalence of zoonotic helminths was higher in stray dogs, in females, in younger ones and in dogs which were not dewormed. Higher infection was found in those pet dogs which were taken out of home for defecation. Despite the risk of helminths to human beings the awareness level was very low. There is need of generating awareness of pet owners regarding periodic anthelmintic treatment of pet dogs and other prevention and control measures. Further, care should be taken towards management of parasitic problems of stray dogs as well in order to reduce the public health risk.

\section{ACKNOWLEDGEMENT}

The sincere thanks go to Dr. Bidur Pya, Dr. Pravin Thapa of Kathmandu Animal Treatment, Centre, Chapalaigaun and Dr. Sudarshan Gautam of Kathmandu Veterinary Clinic, Maharajgunj for their valuable assistance in sampling and surveying. The author also expresses gratitude to Dr. Krishna Raj Pandeya, Mr. Prakash Devkota and staffs of and Central Veterinary Laboratory, Tripureshwor for providing materials and technical helps.

CONFLICT OF INTEREST: None to declare

FINANCIAL INTEREST: None to declare. 


\section{REFERENCES}

1. Rhindali L, Biggeri A, Carbon S, et al. Canine fecal contamination and parasitic risk in the city of Naples (Southern Italy). BMC Vet Res 2006;2:29.

2. Razmi GR. Survey of dogs' parasites in Khorasan Razavi Province, Iran. Iran J Parasitol 2009;4:48-54.

3. Schantz PM. Parasitic zoonoses in perspectives. Int J Parasitol 1991;21:161-170.

4. Traub RJ, Robertson ID, Irwin PJ, Mencke N, Thompson RC. Canine gastrointestinal parasitic zoonoses in India. Trends Parasitology 2005;21:42-48.

5. Kakati K. 2010. Street dog population survey Kathmandu 2010. A report unpublished.

6. World Health Organization. Basic laboratory methods in medical parasitology. Geneva, Switzerland; 1991.

7. Soulsby EJL. Helminths, Arthropods and Protozoa of Domesticated Animals. $7^{\text {th }}$ ed. Bailliere Tindall, London; 1982.

8. Thienpont D, Rochette F, Vanparijs OF. Diagnosing helminthiasis by coprological examination. $2^{\text {nd }}$ ed. Janssen Research Foundation, Beerse, Belgium, 1986; p.9-36 and p.110-127.

9. Giri DR. Screening of Zoonotic helminths in canines of Kathmandu district brought to Central Veterinary Hospital, Tripureshwor (unpublished dissertation). Institute of Agriculture and Animal Science, Tribhuvan University, Nepal; 2010.

10. Swai ES, Kaaya EJ, Mshanga SA, Mbise EW. A Survey on Gastro-Intestinal Parasites of Non-Descript Dogs in and Around Arusha Municipality, Tanzania, Int J Ani Vet Adv 2010;3:63-67.

11. Jones $\mathrm{O}$, Kebede N, Kassa T, Tilahun G, Macias C.. Prevalence of dog gastrointestinal parasites and risk perception of zoonotic infection by dog owners in Wondo Genet, Southern Ethiopia. J Pub Health and Epid 2011;3:550-555.

12. Katagiri S, Oliveral-Sequeeria TCG. Prevalence of Dog intestinal parasites and risk Perception of zoonotic infection by dog owners in Sao Paulo state, Brazil. Zoonoses and public health 2008;55:406-413.

13. Zewdu. E, Semahegn Y, Mekibib B. Prevalence of helminth parasites of dogs and owners awareness about zoonotic parasites in Ambo town, central Ethiopia. Eth Vet J 2010;14:17-30.

14. Degefu H, Tefera A, Yohannes M. Zoonotic helminth parasites in fecal sample of household dogs in Jimma Town, Ethiopia. J Pub Health and Epid 2011;3:138-143.

\section{Citing this article}

Satyal RC, Manandhar S, Dhakal S. Prevalence of gastrointestinal zoonotic helminths in dogs of Kathmandu, Nepal. Int J Infect Microbiol 2013;2(3):91-94. 